Revista de Psicología de la PUCP. Vol. XVII, 1, 1999.

\title{
LA DEPRESIÓN Y LOS TRASTORNOS DE LA ALIMENTACIÓN EN LA MUJER
}

Lillyana Zusman ${ }^{1}$

El incremento del síndrome depresivo y de los trastornos de alimentación en las mujeres es alarmante. Las variaciones del rol tradicional femenino en lo que se refiere a la maternidad y a la función cuidadora de los afectos familiares, su identificación con una pasividad aprendida desde la temprana infancia y la transformación de la estereotipia de los cuerpos femeninos ha determinado la posibilidad de estableccr una asociación entre la depresión y los trastornos alimenticios. El artículo plantea el silenciamiento de la voz como una estrategia aprendida desde la infancia y reforzada en la adolescencia para acallar, reprimir y escindir los despertares a las sensaciones que emanan del cuerpo, al deseo y al goce sexual. El cuerpo se propone como un lenguaje alternativo de características somáticas a través dcl cual se intenta tramitar la escisión del mensaje emocional.

Palabras claves: desórdenes alimenticios, depresión, dieting, dieter.

\section{Depressive syndrome and eating disorders in women}

It is alarming to see the increase of the depressive syndrome and eating disorders in women. The changes in the traditional feminine attitude, concerning maternity and the fulfilment of taking care of the family love, it's identity acquires passively since early childhood and the stereotype of establishing an association between depression and other eating disorders. The article establishes "muteness of the voice", as a strategy learned since childhood and strengthened in adolescence to silence, reprieve and set apart the awakening to the sensations produced by the body towards desire and sexual pleasures. The body responds as an alternative language of somatic characteristics through which it intends to splitting the emotional message.

Key Words: disorders, depression, dieting, dieter.

1. Licenciada en Lengua y Literatura (1982) y en Psicología (1989) en la PUCP. Especialista en terapia de familia y en trastornos de la alimentación. Actualmente realiza estudios de Maestría en la PUCP. Dirección: Teniente Romanet 325 Lima 27. CE:maya@interaccess.com.pe 

Este artículo tiene la intención de establecer relaciones entre algunos conceptos de la psicología actual que en el devenir del desarrollo de la mujer contemporánea van siendo cada vez de mayor importancia. El rol de la mujer, el incremento del síndrome depresivo en mujeres, el tema del cuerpo y sus diversos trastornos y, finalmente, el tema de los desórdenes alimenticios configuran una constelación y abren un espacio para cuestionamientos y enlaces posibles que permiten ir lentamente integrando propuestas teóricas diferentes e intercalando con ellas las observaciones clínicas.

Nos interesa vincular los temas de los Trastornos Alimenticios y la Depresión en mujeres con la finalidad de comenzar a comprender, por ahora desde la teoría, el devenir de la problemática femenina y de los Trastornos de la Alimentación de la mujer en el Perú. Hemos decidido incursionar en horizontes teóricos actuales y novedosos ampliando nuestra perspectiva y dejando de lado intencionalmente, por el momento, los parámetros que rigen nuestra práctica clínica psicoanalítica. Consideramos que es un momento y un espacio adecuado para intentar poner en relación discursos distintos que se generan desde propuestas y experiencias teóricas diferentes. Sin ánimo de validar un nuevo modelo teórico para la comprensión de la depresión en las mujeres y de los Trastornos Alimenticios, intentamos conocer desde diferentes puntos de vista propuestas novedosas acerca de los temas antes planteados.

En los últimos años, el desarrollo del tema de la mujer ha abierto espacios de pensamiento y de cuestionamientos importantes. Estudios que se iniciaron a partir del feminismo con una radicalidad feroz, han tomado un giro significativo desde la perspectiva del género. Autores diversos, desde posturas diferentes, coinciden actualmente en afirmar que el rol de la mujer en la sociedad occidental comienza a ser pensado y re-evaluado a partir 
de eventos tan concretos como el control activo de la natalidad, la postergación de la maternidad en aras de la formación profesional, el acceso de la mujer a puestos de trabajo que anteriormente estaban designados exclusivamente a los hombres, la posibilidad de combinar la maternidad y la profesión, el ingreso de la mujer a posiciones asalariadas igualitarias, el manejo efectivo que hace la mujer de su salario y la consecuente libertad que ella consigue desde la sumatoria de estas y otras posibilidades de comprender su desarrollo. Gilligan (1982), Griffith y Griffith (1994) y otros autores coinciden en afirmar que el cambio en el devenir de la mujer no se ha conseguido sólo a partir de su trabajo y de la consecución de un "sueldo más democrático" sino, fundamentalmente con relación a la posibilidad de las mujeres de ponerse en contacto con las voces de su interior.

L.J. Griffith y M.E. Griffith (1994) consideran que el dilema de las mujeres de nuestro tiempo es que “...la persona se experimenta a sí misma totalmente carente de voz, un tema que ha tomado casi proporciones epidémicas y que se observa en la clínica especialmente en los casos de trastornos de alimentación, abuso de alcohol y sustancias químicas" (p. 98). El autor comenta que deben de existir razones importantes que expliquen la estrecha relación entre la aparición de los síntomas somáticos y la experiencia de no tener "ninguna voz".

"Tener voz" parece ser una frase clave para expresar el cuestionamiento básico de "¿quién soy yo?", pregunta que es difícil de formularse hasta que el sujeto ( $y$, todavía no especificamos a la mujer en particular) no pueda observarse a sí mismo en el contexto de sus interacciones básicas (o primarias) en las cuales desarrolla vínculos afectivos específicos. En relaciones de dependencia, sometimiento y fusión se encuentran las bases de modos de interacción poco saludables que dificultan al sujeto la posibilidad de mirarse con la libertad de un ser independiente.

Muchos síntomas mente/cuerpo se instalan siguiendo a L.J. Griffith y M.E. Griffith (1994) y a Aulagnier (1990) en los dilemas de la dificultad de expresión, es decir, en el "ahogamiento" de las voces interiores que se silencian ante el temor de mostrarse de una manera diferente a la esperada, 
a ser diferente, a revelar lo que no es "revelable", a decir lo que no es "decible" a no encajar en determinadas relaciones que se deben preservar, a perder el sentido estereotipado de la personalidad, etc.

La Psicología Clínica ha demostrado cómo silenciar la propia voz es una estrategia convencional para proteger una relación vital. Así mismo, ha mostrado también que silenciar el propio cuerpo es una tarea bastante difícil, aunque también posible, y que, pese a la dificultad que ésta entraña, el sujeto, al crecer, suele aprender a desligar su cuerpo de su discurso privado a medida que aprende a competir en las sociedades modernas dentro de un discurso público muy lejano al privado.

La escisión del lenguaje y el silenciamiento del cuerpo constituyen el terreno donde crecen y se desarrollan los síntomas somáticos, siendo la somatización un lenguaje corporal del orden del lenguaje no verbal que tiene un discurrir distinto y separado del lenguaje verbal y que se utiliza cuando las expresiones de la emoción se atenúan hasta desaparecer.

\section{La mujer y su cuerpo a finales del siglo $X X$}

La historia del desarrollo de la sociedad occidental ha demostrado un incremento alarmante de los trastornos alimenticios en los últimos 25 años. De un lado, la sociedad impone progresivamente patrones, cada vez más exigentes de feminidad, patrones que devienen en estereotipos socioculturales a los que las mujeres deben acceder para ser "parte de...", un espacio imaginario que obliga o determina a "reducirse" a las "proporciones de la cultura". De otro lado, la búsqueda de un espacio femenino ha determinado colocar el cuerpo y depositar en el cuerpo un conjunto de, aquello que Griffith y Griffith (1994) denominan "el dilema de lo no decible". Esto quiere decir que, de alguna manera, la mujer contemporánea $y$, lo que es mas grave, la joven actual coloca en el cuerpo aspectos históricos y regresivos "no decibles" como si decirlos determinara una amenaza a su posición socio emocional".

1. La variada literatura acerca de los Trastornos de Alimentación sugiere que la reducción del cuerpo a proporciones tan increíbles puede estar también vinculada al intento de la mujer a "igualarse" 
La Anorexia Nervosa, la Bulimia, el Trastorno Yo-Yo Dieting y el Binge Eating se constituyen como síndromes psicosomáticos en la sociedad contemporánea. Se organizan como "nudos" en los cuales se entrecruzan vivencias múltiples individuales, familiares, socio-culturales que terminan por resultar incomprensibles e insoportables para quienes las viven. El "colocar" la confusión y el dolor en la comida, un objeto externo, medible y supuestamente manejable, permite situar el dolor y el sufrimiento "afuera" para tratarlos como cosas que se controlan desde la fuerza y la voluntad.

Cuando intentamos abordar el tema de la alimentación, en general, y de los trastornos de la alimentación, en particular, tenemos que considerar dos factores centrales que nos permiten contextualizar el tema. Por una parte, la realidad de estar al borde del fin de siglo y de que, desde hace aproximadamente dos décadas, los conceptos del peso, del cuerpo, de la tecnología para modelar el cuerpo, de la cosmética, etc. se han modificado sustancialmente en aras de crear un prototipo de cuerpo/peso ideal que se ha convertido en un valor fundante para el individuo de las sociedades occidentales industrializadas. Por la otra,, el hecho de que la adolescencia es la etapa más variable del ser humano en tanto que supone, de un lado, una confirmación de la maduración del cuerpo, la sexualidad, la moral, los valores, los intereses, etc. y del otro, una cierta vulnerabilidad por encontrarse muy cerca de las presiones y exigencias socio culturales especialmente, las vinculadas a los estereotipos culturales.

\section{La depresión en la mujer}

Los altos índices de depresión en mujeres en los últimos 20 años ha determinado que muchos investigadores se cuestionen el por qué de este fenómeno e intenten proponer explicaciones desde la biología hasta las complejas perspectivas interdisciplinarias.

con el hombre a través de la negación de las formas femeninas de su cuerpo. La mujer intenta, a través del ejercicio físico "crear" un cuerpo atlético de características similares a las masculinas, cuerpo que le permita borrar la diferencia inherente a los sexos. 
Uno de los cuestionamientos importantes de esta época es si la depresión, como síntoma de la mujer es un cuadro psicopatológico específico o, en tanto conjunto de síntomas, un componente estructurante de la definición de ser mujer. Es interesante señalar que los autores coinciden en que la depresión es una experiencia que las mujeres suelen identificar como propia y, por lo tanto, atendiendo a la frecuencia de este síndrome en el género femenino, se sugiere que, probablemente, no se trate de una "enfermedad" en el sentido médico de la palabra, sino de una distorsión o de una exageración del estado normativo de ser mujer en las sociedades occidentales. Los periodos depresivos son, por lo general, normales y, en este sentido, se habla de un cuadro depresivo propiamente dicho cuando los síntomas comienzan a interferir con el funcionamiento individual, afectivo, intelectual y social. Estudios transculturales acerca de la depresión en mujeres demuestran que la depresión femenina es una constante cultural y no una ocurrencia privativa de las sociedades occidentales.

El tránsito de la mujer de la perspectiva tradicional hacia la perspectiva moderna determina que la posición y el status que ésta adquiere en la sociedad sea ambivalente. La experiencia de la maternidad y los valores emocionales y morales vinculados a ella inclinan la balanza hacia una orientación tradicional, aquella que sirúa a la mujer en los roles de madre, esposa y ama de casa y el desarrollo de la posibilidad intelectual/profesional inclina la balanza directamente hacia el lado opuesto, incentivando el desarrollo individual y la libertad emocional. Esta ambivalencia genera en la mujer una suerte de caos y de cuestionamientos profundos que arrancan de la esencia misma de la feminidad, pasando por la maternidad y desembocando en la todavía confusa situación de ser mujer/profesional, categoría que, aún en los albores del Siglo XXI, no termina de ser una posibilidad real.

La Psicología Cognitiva y la Psicología del Desarrollo enfatizan que la depresión no está exclusivamente vinculada a la pérdida de un objeto o a la pérdida del afecto del mismo, sino a la pérdida del valor en una relación de mutualidad afectiva. No se pierde, entonces, al objeto de la relación sino al contenido de la misma. 
En el flujo de comunicaciones empáticas y de atención mutua con la madre, el niño adquiere la sensación de ser cuidado y empieza a desarrollar un sentido de sí mismo como sujeto y de cuidado por el self como si de él se derivara la fuerza y la competencia de sus capacidades relacionales. En este sentido, la pérdida o la consecuente sensación de pérdida no está en relación sólo a lo que puede ser provisto o retirado por el otro (equivalente al objeto y/o al afecto de un objeto) sino a la posibilidad de poder o no poder tomar parte en una relación de afirmación de mutualidad para estar conectado afectivamente con los otros. Esta conexión afectiva de participación dinámica en una relación supone, como parte del proceso, la validación del propio self como una persona en relación. La ausencia de la capacidad para conectarse con los otros, la negación de la oportunidad para un desarrollo integral de las metas y los proyectos es el marco de los efectos de la pérdida. Lo que se pierde, entonces, es la capacidad de ser $y$ de estar en el mundo.

La madre, en su calidad de mujer, facilita y alienta el crecimiento emocional y las conexiones entre los miembros de la familia procurando mantener en cada uno de los mismos una articulación adecuada de su self la cual debe tomar en cuenta sus capacidades, necesidades, impulsos y deseos. Sin embargo, parece que la función del padre y de la cultura (la crisis edípica desde el punto de vista psicoanalítico), es separar al niño de sus objetos primarios de amor y de deseo e insertarlos asertivamente en la cultura. La niña, a diferencia del niño, se queda cerca de la madre y registra junto con ella todo el conjunto de necesidades y obligaciones diseñadas para el rol de ser madre y de ser mujer, categorías que, por lo general, son todavía difíciles de diferenciar. La niña absorbe, por lo tanto, un modelo de responsabilidades especialmente en lo que se refiere al cuidado y al mantenimiento de relaciones intra e inter familiares. Al igual que su madre, alentará el crecimiento de un self diferenciado, self que corre paralelo al desarrollo de las capacidades del self relacional y de las posibilidades de ponerse en contacto con las cadenas de relaciones que lo instalan en la red social. El nuevo modelo de comprensión del desarrollo psicológico de la mujer la sitúa en un proceso de crecimiento al interior 
de una relación, entendiendo la relación como un vínculo en el que se crea y re-crea permanentemente la capacidad para sintonizar afectivamente. Esta sintonía es un proceso de interacción bi-direccional en el cual muruo en el cual las dos partes buscan encontrarse en la empatía.

Weisman (1986), atendiendo a la participación de factores genéticos, endocrinos, puberales, psicológicos, de abuso sexual y socio culturales, considera que la mujer está en una posición de desventaja que la hace más vulnerable a la depresión. La autora plantea dos hipótesis que intentan explicar el síndrome depresivo en la mujer.

\section{Hipótesis del "status social"}

La discriminación abierta y natural hacia la mujer dificulta que ella pueda alcanzar eficiencia, dominio, poder, autoridad en su acción y asertividad y esto contribuye a su aflicción y a su pena psicológica. La desigualdad y la supuesta dependencia establecida hacia los otros generan en la mujer una baja sustantiva en su autoestima y el detrimento de sus aspiraciones con la consecuente pérdida de asertividad.

\section{Hipótesis aprendida de "helplesness"2}

El condicionamiento social y las imágenes estereotipadas producen en la mujer un sentimiento de minusvalía que actúa en contra de la asertividad femenina. Este aspecto es reforzado, desde la infancia, por las experiencias sociales/afectivas que rodean a la niña en su desarrollo. Las niñas/jóvenes absorben una imagen de minusvalía desde su infancia y aprenden, en consecuencia, a sentirse desamparadas y abandonadas a lo largo de su tiempo de socialización, experiencia que genera un bajo repertorio de respuestas en sus posibilidades de afrontar el estrés.

2. La traducción de la palabra "Helplesness" es abandono, desamparo (1995), Random House, Ballantine Books, New York. 
La autora considera que los elementos claves para comprender la depresión en las mujeres se vinculan con la vulnerabilidad femenina ante la pérdida, la inhibición de la acción o la asertividad, la inhibición de la rabia y de la agresión (condicionamiento fundante de los desórdenes alimenticios) y la baja autoestima.

La práctica terapéutica con mujeres deprimidas revela que los síntomas recurrentes por los cuales las mujeres asisten a consulta son: la sensación de "badness" autenticidad y la falta de reconocimiento de los impulsos. Si nos remitimos a la propuesta de Gilligan (1982) el acallar las voces que vienen de dentro y el operar fuera en un "como si...no pasara nada por dentro", termina por "asfixiar" a la mujer y remitirla a una depresión. El dilema de lo no decible está en el hecho que la mujer no se puede afirmar y mostrar como un ser con vida propia ya que su destino, desde su género, está vinculado a servir y a cuidar los demás. Este es un principio fundante del vínculo primario con la madre a partir de una crianza que no invita a la realización de la individuación del self sino, mas bien, al cuidado de las interacciones intra e interfamiliares. Gillingan (1982) afirma: "...girls emerge from this period with a basis for 'empathy' built into the primary definition of self in a way that boys does not" (pp. 8) . $^{4}$

Para las niñas y las mujeres, comenta Gilligan (1982) los asuntos de la feminidad o de la identidad femenina no dependen del logro de la separación de la madre o del progreso de su individuación, sino, mas bien, se define por el apego. La masculinidad, en cambio, se define por la separación. La identidad de género masculino está amenazada por la intimidad, lo que dificulta, en alguna medida, que los hombres tengan dificultades en sus relaciones, mientras que la identidad de género feme-

3. Una traducción adecuada de "badness" es maldad, mala calidad, lo malo (1995), Random House, Spanish-English Dictionary, Ballantine Books, New York.

4. Gilligan,C. (1982). In a Different Voice. Cambridge, Harvard University Press, pp. 8. Las niñas emergen de este periodo con una base de 'empatia' construida en la definición primaria de su self en una forma en la que los niños no lo hacen. 
nina está amenazada por la separación, lo que, finalmente. Determina que las mujeres tengan dificultades en sus procesos de individuación.

Weissman (1986), al referirse a los factores predisponentes a la depresión femenina, enfatiza que la llegada de la pubertad en las niñas moviliza en ellas los aspectos psicológicos más profundos de la misma y las confronta con variables estados de ánimo que tanto para ellas como para quienes las rodean son difíciles de comprender.

\section{La Pubertad, los cambios fisicos y la necesidad de adaptación}

La pubertad se presenta como una etapa de cambios físicos y de maduración sexual que influye en la vida sexual del púber, en la representación de su imagen corporal, en la aparición y la declinación de sus intereses y actitudes $y$, finalmente, en los nuevos poderes y sensaciones físicas adquiridas. Son cambios que tienen un contenido y una cualidad muy flexibles. El tiempo de duración de la pubertad es variable. La edad no es un indicio ni marca un hito en el desarrollo; es sólo un índice de que algo comienza y de que algo está por terminar ya que el patrón de crecimiento en los niños no es uniforme. El incremento de tamaño, por ejemplo, no corresponde con el grosor del cuerpo ni tampoco con el desarrollo de las características sexuales primarias y/o secundarias. El crecimiento es una secuencia de cambios súbitos mas que una progresión gradual y suave y, en este sentido, la correspondencia de los cambios físicos con los cambios emocionales no es necesariamente adecuada. Lo desigual de este proceso determina exigencias diversas de adaptación física y emocional en los jóvenes debido a variaciones que, en muchos casos, él mismo no comprende. A lo largo del proceso de la pubertad, las niñas se sienten más incómodas con el peso que ganan y con las marcas definidas de su cuerpo, marcas que, además, van en contra de los modelos de cuerpos prepuberales idealizados por la moda y la belleza y validados por la cultura.

El paso por la pubertad es diferente para los niños que para las niñas. La joven inicia un periodo que va a estar definido por una suerte de inestabilidad en la cual se pueden apreciar momentos depresivos muy 
significativos. Nolen Hoeksema (1995) afirma que los rasgos depresivos en la joven no están directamente relacionados con los cambios hormonales sino, mas bien, con la aparición de las características sexuales secundarias ya que afectan directamente a la representación del self y a la autoestima. A lo largo del periodo de la pubertad, las niñas valoran más los cambios de su cuerpo que los niños, para quienes el cuerpo es mas una fuente de poder y de posibilidades de penetración en el mundo de los grandes. Las niñas que desarrollan una imagen corporal adecuada y que se sienten cómodas y contentas con la misma, tienen un mayor nivel de autoestima. En cambio, niñas que no están contentas con su imagen corporal están en mayor riesgo de presentar síntomas depresivos y posibles trastornos alimenticios.

Los cambios corporales que se presentan a lo largo de la pubertad ${ }^{5}$ generan en ambos sexos una preocupación severa respecto de su cuerpo ya que se trata de un cuerpo en evolución constante, una evolución impredecible que no está sujeta al control por parte del individuo, que genera incertidumbre, que puede devenir en "normal" pero que también puede presentar problemas mayores o menores, como, por ejemplo, la obesidad y/o el acné. Los jóvenes se mantienen en crisis permanentes que dificultan la intervención de los padres, a quienes se tiende a rechazar de plano como la intervención del médico y/o del terapeuta por temor a que se pueda descubrir alguna anomalía del cuerpo o de su desarrollo físico o emocional.

Es natural que los jóvenes tiendan a comparar los cambios que se producen en su cuerpo con los que se producen en los cuerpos de sus compañeros. Para los adolescentes el grupo de pares es fundamental. Puede ocurrir con frecuencia que, a pesar de la coincidencia en cuånto a la edad cronológica, se presenten discrepancias en el grupo de pares en cuanto a la maduración física y que estas discrepancias terminan marcando el destino

5. En las niñas aparecen como rasgos saltantes la menarca y el desarrollo de los senos y en los niños aparecen cambios en la voz, cl vello facial, la maduración de los genitales y las alteraciones en el ciclo genital. 
de los individuos y la formación de grupos: los más desarrollados se agruparán de una manera y socializarán también de cierta manera mientras que los menos desarrollados lo harán de otra. La convergencia de los modos de crecimientos con los modos de socialización nos da una pauta de las múltiples variables con las que se confrontan los jóvenes a partir de una maduración sobre la que ellos tienen en un primer momento escaso control porque se trata "inicialmente" sólo de una maduración biológica.

El conjunto de cambios físicos que imprime la pubertad en el joven requiere paralelamente de un correlato adaptativo en el ámbito psicológico. La adolescencia es la etapa en la que confluyen todos los esfuerzos por ajustarse a las diversas condiciones externas e internas que confronta el individuo. Es, en otras palabras, el proceso de adaptación psicológica a los procesos de maduración física.

La irregularidad en la aparición, duración y terminación de la pubertad es sorprendente. Su variabilidad es tan grande que no se puede establecer una correspondencia entre los cambios que se producen en los terrenos fisiológico, anatómico, mental y emocional. La historia pasada de cada individuo, es decir, su infancia es un hito importante de considerar ya que se ha comprobado que individuos bien avenidos, con historias personales y familiares "suficientemente sanas y saludables", tienen mayores posibilidades de ingresar a la adolescencia con tranquilidad y tolerancia que aquellos que han pasado por una infancia dificil.

A lo largo de la adolescencia, el individuo tiene que elaborar las exigencias que le imprimen las experiencias de la vida para finalmente, arribar a un Yo estable y a una organización adecuada de los impulsos. Esta etapa supone un segundo paso hacia la individuación y a la formación de una identidad, procesos que se logran a través de la renuncia a los objetos de amor primarios y a la organización paulatina en torno a objetos de amor externos, al grupo, a los variados intereses de corte moral, intelectual, social y profesional. Este proceso que, por definición, es "natural" confunde al adolescente y lo remite, por momentos, a la soledad y al aislamiento. Debold, Wilson y Malavé (1994) afirman: "Durante la adolescencia se 
produce un estira y afloja de las presiones por el que las jóvenes renuncian a partes de sí mismas para convertirse en lo que nuestra cultura considera como una mujer. Ciertamente, el tipo de cambios que hemos experimentado como cultura ha sido la causa de trastornos y confusión a lo largo de generaciones. Las crecientes libertades han sacado a la luz angustias ocultas que permanecían en la sombra y de las que ni siquiera de hablaba"6.

Gilligan (1982) considera que el periodo de la adolescencia se presenta como una "crisis de conexión", como una época e la que las chicas tienen que pasar a través de un "muro", es decir, a través de las propuestas de la sociedad patriarcal en la que vivimos. En este proceso, las jóvenes se desconectan de la relación que mantienen consigo mismas para sumergirse en otro tipo de relación, fundamentalmente, aquella que viene determinada por el afuera.

\section{La adolescencia y el cuerpo}

El paso por la pubertad y el ingreso a la adolescencia nos invita a pensar que el punto nodal sobre el cual se anuda la identidad durante la adolescencia es el cuerpo. Con el paso de la historia y el devenir del tiempo, esto no significaría ningún problema si, hacia fines del siglo XX, la cultura en las sociedades industrializadas no hubiese propuesto como un ideal un determinado tipo de cuerpo y un cierto promedio de peso como centros gravitantes de la identidad.

El periodo adolescente es complicado. Las jóvenes no viven su adolescencia como un periodo de "expansión", como normalmente se esperaría sino como un periodo de "contracción", por la movilización de la estructura de sus afectos en torno al nuevo cuerpo. Ellas tienen que resolver sus capacidades siendo pasivas y hasta masoquistas, preparándose para la sumisión a los hombres vía la maternidad. Los jóvenes, por el contrario, viven en expansión y apertura. Debold, Wilson, Malavé (1994) consideran

6. Debold, E., Wilson, M. Malavé, I. (1994), La Revolución en las relaciones madre hija pp. 38. 118 
La depresión y los trastornos de la alimentación en la mujer

que los adolescentes pasan por periodos de profundos sufrimientos. "Cuando el mundo empieza a abrirse para ellas, muchas se encuentran psicológicamente angustiadas...las muchachas sufren, en un grado muy superior a los chicos, depresión, insatisfacción con su estado físico, trastornos de la alimentación (que van desde la Anorexia Nervosa hasta la Bulimia), estrés y otras manifestaciones de sufrimiento psicológico. Las alteraciones de la alimentación y los embarazos adolescentes, que una vez estuvieron asociados con los extremos opuestos del espectro de las clases sociales, están hoy más presentes que nunca en las muchachas de todas las clases y razas...Los investigadores han descrito que lo que les sucede a las jóvenes como un 'cuadro de trastornos silenciosos' es debido a que las chicas difieren de los chicos en su forma de experimentar la ansiedad. Los muchachos tienden a expresarse, a lanzar su angustia al mundo que los rodea por medio de la delincuencia y de las conductas agresivas. En cambio, las jóvenes, tienden a tragarse 7 su dolor, a interiorizarlo, y de esta forma acaban acumulando ansiedad y sufriendo depresiones. Se acusan a sí mismas por sentirse mal y se autodestruyen con el peso de la culpabilidad. ...Este silenciamiento de las jóvenes, unido a la interiorización por su parte del dolor y la angustia, hace que aunque internamente pidan socorro a gritos, su voz sea difícil de oir y fácil de ignorar" ${ }^{\text {. }}$

El Psicoanálisis y la Psicología del Desarrollo coinciden en señalar que las niñas aprenden a no mostrar su percepción corporal, sus deseos y sus necesidades hasta que éstas tengan la oportunidad de transitar a través de los hombres. Es casi como que se nace sabiendo que las sensaciones que emanan del cuerpo son inaceptables.

Este tipo de mensajes "paralizantes" deja a la niña en la necesidad de buscar una solución que intente mantener sus construcciones psicológicas acerca del cuerpo y sus cambios fuera de sí misas. La niña, que vive con la sensación y el temor de expresar su sexualidad y sus deseos sexuales, se

7. Uso la cursiva, a diferencia de lo hecho en la traducción original, por lo sugerente que me parece esta expresión en relación a los trastornos de la alimentación.

8. Debold, D., Wilson, M. Malavé, 1. (1994) pp. 34-35. 
coloca de antemano en una posición de pérdida. El conflicto es muy grande. La aparición en el cuerpo de características femeninas en un estado en el que el self se encuentra todavía en el tránsito de la infancia a la adolescencia puede tener efectos negativos en las adolescentes en desarrollo. Al encontrarse las jóvenes con cuerpos formados, desligados de experiencias emocionales de soporte y de acompañamiento así como del estigma cultural de "hacerse mujeres", condición que no queda muy clara para las adolescentes, puede traer consecuencias importantes en sus vivencias, sus pensamientos y su aceptación del cuerpo.

En un primer momento, el cuerpo se escinde. Ser mujer, tener un cuerpo femenino notable y asumir las funciones femeninas es una situación muy comprometida en la mayoría de jóvenes. La niña ha sido enseñada desde la temprana infancia, de acuerdo a ciertos preceptos de la sociedad occidental, a esconder su cuerpo y las sensaciones que emanan de él. El cuerpo tiende a despojarse de sus instintos, algunas veces, suavemente, otras, con una intensidad que se desborda.

Una relación empática con la madre así como una relación flexible y adecuada con su sociedad se organizan como espacios emocionales que le dan la bienvenida a su cuerpo y su sexualidad y que le facilitan una experiencia emocional de goce. Se trata de un cuerpo catectizado. Sin embargo, si este no es el devenir natural, el cuerpo y la mente se disocian, pudiendo seguir caminos diferentes teniendo cada uno de ellos un lenguaje propio: la mente se organiza en torno al lenguaje verbal y el cuerpo, en torno al lenguaje somático.

\section{El lenguaje del cuerpo}

Durante los últimos veinte años, los países desarrollados que dictan las normas a las que se ciñe la sociedad occidental ha replanteado el valor asignado al cuerpo. De pronto, la concepción del cuerpo y del peso, así como de los modos de tratarlo y de la moda han dado un giro significativo especialmente dentro del género femenino. Los cuerpos gruesos que anteriormente eran símbolos de salud y de bienestar son, actualmente, sím120 
bolos de falta de valía personal y pobre autoestima; los cuerpos de caderas redondeadas y bustos prominentes, símbolos de la maternidad, han dado lugar a los cuerpos delgados y atléticos que casi consiguen anular los caracteres femeninos en una relación cuasi competitiva por adquirir formas masculinas.

Este cambio ha podido sostenerse y magnificarse, así como mantenerse encapsulado en el principio de la salud, el cual prescribe regímenes de alimentación más livianos, más ordenados, más metódicos, más saludables, etc. que los regímenes del pasado. De pronto, el estar delgado es un valor de salud que significa alejarse del colesterol, el azúcar, de las grasas, de los problemas cardiovasculares, etc.. El estar delgado "por salud" puede entrar en colusión con el valor socioculturalmente asignado al peso y al cuerpo $y$, en este sentido, es que se pierde la independencia entre ambos rubros.

La sociedad impone una cierta obligatoriedad para conseguir un cuerpo no natural. Los patrones de belleza, de formas de cuerpo, de pesos varían con el tiempo y los contextos histórico-sociales. La evidencia muestra que las mujeres han tratado a lo largo de la historia, mas que los hombres, de modificar su aspecto, su peso y su cuerpo y eso se debe, nos aseguran los científicos sociales, a una percepción por parte de la mujer de tener un cuerpo incompleto, antigua reminiscencia a la perspectiva fálica de la teoría freudiana, que plantea que los hombres "tendrían" algo que a las mujeres les falta: el pene. La falta de diferenciación entre pene, como objeto concreto, $y$ falo ha determinado la elaboración de variadas metáforas (todas compensatorias) asociadas a la belleza y al peso. Así, el descontento de la mujer es tanto mayor que en el hombre y lo más lamentable es que esta percepción la toman las jóvenes como "natural" casi desde el inicio de la adolescencia.

La industria cosmética y la tecnología han invertido millones de dólares para favorecer el ideal de belleza contemporáneo. Los programas de dietas asociados a alimentos, bebidas, medicinas, fórmulas light que se venden en lugares específicos, toda la parafernalia que rodea a los ejercicios 
(asociados o no dietas específicas), cosméticos, moda, cirugía cosmética, como implantes en partes de la cara y en los senos y la liposucción son parte de la realidad cotidiana de la mujer actual. Parecería, desde este contexto, que el ideal de belleza es posible para "cualquiera que se esfuerce lo suficiente, trabajando su cuerpo, ejercitándolo y restringiendo la comi$\mathrm{da}$ ". Así, la apariencia deviene en un valor sobre dimensionado mientras que los valores afectivos y familiares pasan a segundo plano y los "looks" son fabricados a través de cuerpos objetivados. Si seguimos en este planteamiento, podríamos afirmar que las mujeres son casualidades de la tecnología.

Los jóvenes adolescentes que van creciendo naturalmente preocupados por el cuerpo y sus vicisitudes ingresan al mundo de los adultos con pautas marcadas para un ingreso más-menos bien avenido. En una parodia del proceso natural de selección "de la especie", los delgados van a un grupo y los gruesos a otro, los altos van a un grupo y los bajos a otro, etc.

¿Qué libertad encuentran, entonces, los adolescentes para tomarse el tiempo que su desarrollo genético, biológico, maduracional le imprimen a su cuerpo? ¿Tiene el adolescente tiempo para encontrarse en una nueva estructura corporal y adaptarse a ella? ...O, ¿será que el temor a no pertenecer al tipo del grupo dominante los obliga a tomar medidas de precaución antes de tiempo, como, por ejemplo, hacer dietas "por si acaso"?

Hacia fines de siglo, nos enfrentamos a una situación verdaderamente peligrosa. El estereotipo cultural habla de un determinado tipo de belleza así como de un determinado peso y cuerpo de formas específicas que se consiguen gracias a los avances de la tecnología y e la cosmética. A este proceder se suman ciertas tendencias de la moda para gente delgada, generalmente, en el caso de las jóvenes, muy insinuante y, en el caso de los mayores, un estilo "muy profesional" que es similar a la moda masculina. Dentro de este esquema, el cuerpo es tratado como una cosa que se maneja de acuerdo a pautas específicas y que se moldea a voluntad. ¿Dónde queda la carga genética, las determinaciones biológicas, las alteracio- 
nes maduracionales, las complicaciones de una determinada enfermedad? ¿Qué cabida tienen? Una de las posibles consecuencias de no poder moldear el cuerpo al antojo es la aparición de algún tipo de trastorno alimenticio.

El concepto de thinness o la delgadez simbolizan la competencia, el control, el éxito y el atractivo sexual. El concepto de obesidad, por el contrario, simboliza la flojera, el self indulgence o consentimiento indiscriminado del self y la falta de voluntad. El modelo de la mujer actual es el modelo de pasarela: es decir, una mujer con un peso y un cuerpo que, por lo general, está por debajo de la norma general.

Los investigadores actuales consideran que los desórdenes alimenticios de esta época son síndromes culturales que no pueden ser comprendidos fuera de un determinado contexto. El valor cultural asociado a la delgadez y a la obesidad alientan la tendencia a los individuos, en general y las mujeres, en particular, a bajar exageradamente de peso, un camino que puede conducir al desarrollo de los desórdenes alimenticios.

Los trastornos de la alimentación, que hasta hace algunos años se presentaban casi exclusivamente en las sociedades industrializadas, en grupos étnicos blancos, en clase social media-alta y entre mujeres, han comenzado a presentarse también en grupos minoritarios y de migrantes de ciudades pequeñas y/o subdesarrolladas a ciudades grandes, por lo general, industrializadas como un intento de adaptarse a los patrones de la sociedad dominante.

\section{El "dieting" y sus implicancias: un proceso cotidiano}

El dieting ${ }^{9}$ es el proceso de hacer dietas que intenta reemplazar a la regulación normal del hambre, aquél que proviene del impulso biológico. Este proceso se constituye como un plan cognitivamente determinado que

9. Dieting es una palabra que no tiene traducción exacta al español y que para fines de este trabajo la voy a mantener en inglés, fundamentalmente por su condición de verbo substantivado (gerundio) que sugiere la idea de un proceso continuo. 
apunta a ayudar a quien lo practica a bajar de peso y/o a mantenerse en un peso bajo. Para cada dieta y para cada proceso de dieting hay un dieter ${ }^{10}$ específico. Una característica común a todos los dieters es que deben ignorar e ignoran las señales internas del hambre biológico que provienen de su organismo en aras de adecuar su organismo, su deseo y sus necesidades a un plan establecido desde afuera. Desafortunadamente, el aprender a ignorar las señales del hambre, premisa fundamental de los dieters, es una matriz de desórdenes alimenticios.

Existen varios tipos de dieters. Los "normales" son los que se cuidan permanentemente de la comida y que pueden entrar y salir del proceso de dieting sin conflicto; los restringidos son aquellos que restringen su alimentación a lo básico y que no pueden salirse de la dieta sin generar un caos interno; aquellos a los que denominamos "intermedios", tienen dificultades para instalarse en un sistema adecuado, flexible y permanente de alimentación y, por último, los "Yo-Yo Dieters", el grupo más peligroso por ser el más encubierto y el más aprobado socialmente.

En el artículo "Dieting and Eating Disorders", Polivy y Herman (1995) sugieren que existen diferencias entre los dieters crónicos y restringidos y los "más-menos normales". Con relación a la comida y al acto de comer, los crónicos sienten permanentemente que "han quebrado la dieta" y el acto de reparación no consiste en auto regular nuevamente su ingesta sino, por el contrario, en ingresar en un periodo de caos en el que arrancan a comer más y más. Ellos son casi incapaces para decodificar las señales internas reguladoras del hambre. Esta suerte de alexitimia termina gobernada desde fuera a través del éxito o del fracaso en el manejo de sus dietas. El mal manejo del "hambre" y de la comida tiene repercusiones en las diferentes áreas del self del sujeto.

En el ámbito emocional, los dieters crónicos tienden a comer más en periodos de tensión, justamente para aplacar su angustia. Son sujetos con

10. Dieter es una palabra que tampoco tiene traducción al español pero que significa algo así como "dietófilo". 
una personalidad frágil, una autoestima pobre y una sensación de poca valía personal. Por lo general, compensan su sensación de minusvalía exagerando al igual como se hace con a comida. A nivel del peso, los dieters crónicos tienen menos posibilidades de mantener un peso estable: sus pesos fluctúan mucho más que los de los dieters normales o intermedios. Desde lo cognitivo, su pensamiento gira en torno a la comida y a la valoración de muchas de sus actividades está en función al comer. La comida se "interpreta" como gratificante, generadora o provocadora de culpas. Los dieters tienden a pensar más y a organizarse más en tono a la comida que aquellos que no son restrictivos.

En todos los casos, la dieta se entiende como un proceso regulador -que actúa desde afuera- de la sensación interna que se denomina hambre. La dieta se crea justamente para reemplazar aquello que se quiere negar: la sensación ligada a lo somático. De la negación primaria del hambre, se desprende el desconocimiento o la negación de la sensación de saciedad. Los sujetos envueltos en estos procesos dejan de saber cuándo están llenos y, lo que es más grave, cuándo están satisfechos con lo que han comido. El dieting es una causa necesaria pero no suficiente para producir un desorden alimenticio. Para que se pueda establecer una relación adecuada entre ambas ocurrencias, es necesario detenerse y examinar al dieter, el proceso de dieting, el contexto en el que se desarrollan, los factores que lo influyen positiva y negativamente. Es claro que los antecedentes personales del sujeto que enferma así como su historia familiar son determinantes en la comprensión del caso.

Es claro que existen muchas dietas, muchos tipos de dieters y muchos contextos en los que se realizan de una manera particular la relación dieter/ dieting. Esta reflexión nos obliga a plantear que no hay dieter sin dieting en una circunstancia psicológica específica.

Es, entonces, el estar delgado sólo una cuestión de estética que garantiza la presencia social? El trabajo con mujeres con desórdenes alimenticios demuestra que los procesos de dieting se relacionan directamente con dificultades de autoestima, sensaciones deficientes de valía personal, per- 
cepción deficiente de asertividad, dificultades de interrelación y dificultades familiares. Las condiciones previas al trastorno psicosomático son similares a las que se encuentran en la clínica de mujeres deprimidas. No es casual, por lo tanto, establecer una relación entre la depresión y los trastornos alimenticios en las mujeres. Es como si el dilema de lo no decible, aquello que se somatiza, se coloca de manera alternativa en el retiro afectivo de las interacciones personales y/o en el cuerpo manejado al compás de las emociones.

En este sentido, se considera que el dieting está directamente asociado, a mayor o menor plazo, con el desarrollo de trastornos alimenticios. Pacientes con bulimia han reportado que se iniciaron en conductas binge eating y purgativas mientras hacían sus primeras dietas.

La llegada de la pubertad y, finalmente, de la adolescencia supone para los jóvenes, en general, y para las jóvenes, en particular, una etapa de dificultades y sufrimientos que se expresan en el ámbito de las emociones y del cuerpo. Las jóvenes se encuentran en el camino de asimilar e internalizar los procesos puberales así como las exigencias que impone la sociedad en lo que a los valores femeninos se refiere. El cuerpo se convierte en un generador $y$ un receptor de sensaciones y vivencias somáticas que despiertan a la joven a la confrontación con la sexualidad, la libertad, el poder, las posibilidades y los nuevos intereses. Estas nuevas sensaciones que se vinculan con afectos específicos deben ser silenciados y reprimidos para encontrar concordancia con el modelo social dominante y ser negociadas para no sobresalir en un medio en el cual la voz debe ser silenciada, el cuerpo reducido y el ánimo deprimido.

Los desórdenes alimenticios, sean incipientes o avanzados, no son sólo problemas de peso y de alimentación. Son sólo síntomas de un conjunto de problemas emocionales que, por alguna razón, no han podido expresarse sino a través de un desorden psicosomático. Los tratamientos son largos y costosos. Es más, alentadores por momentos y frustrantes por otros. Descomponer la lógica de un trastorno alimenticio es un proyecto de largo alcance cuyos resultados, en la mayoría de los casos, es incierto. 
Existen distintos tipos de tratamientos: desde los estrictamente conductuales (modificación de la conducta) hasta los ortodoxamente psicoanalíticos incluyendo los médicos. Hoy en día, se ha comprobado que la sola modificación del síntoma o su eliminación, en el mejor de los casos, es una técnica que garantiza pobres resultados . Estudios recientes demuestran que, a pesar de la dificultad y el tiempo, estos casos se benefician más de una relación interpersonal entre terapeuta-paciente, una relación que permita explorar la lógica interna, el enclave del desorden y transformar la actuación permanente del síntoma (no comer, comer exageradamente, vomitar o alternar ambas conductas) en afectos.

\section{Referencias}

Aulagnier, P. (1990). Cuerpo, Historia, Interpretación: De lo originario al proyecto identificatorio. Buenos Aires: Paidós

Debold, E., Wilson, M., Malavé, I. (1994). La Revolución en las Relaciones Madre-Hija. Barcelona: Paidós.

Gilligan, C. (1982). In a Different Voice: Psychological Theory and Women's Development. Cambridge: Harvard University Press

Griffith, L.J y Griffith, M.E (1994). El cuerpo habla: Diálogos terapéuticos para problemas mente-cuerpo, Buenos Aires: Amorrortu Editores.

Nolen Hoeksema, S. (1995). Epidemiology and Theories of Gender Differences in Unipolar Depression. En Nolen Hoeksema (Ed.), Gender and Psychotherapy (pp. 63-87). Nueva York: American Psychiatry Press.

Polivy, J. y Herman, P. (1995). Dieting and it's Relation to Eating Disorders. En K.D Brownell, y C.G. Fairburb (Eds.), Eating Disorders and Obesity: A Comprehensive Book (pp. 83-95). Nueva York: The Guilford Press 
Surrey, J.L. (1996). The Self in Relation: A Theory of Women's Development En J. Jordan, A.C. Kaplan, J. Baker Miller (Eds.), Women's Growth in Connection (pp. 51-64). Nueva York: The Guilford Press. Weissman, M. (1986). Depression. En A.M. Brodsky y R. Hare Mustin (Eds.), Women and Psychotherapy (pp. 97-111). Nueva York: The Guilford Press. 